\title{
Thallium isotope ratios record a transition to melting of hydrated oceanic crust at the Hadean-Archean boundary
}

\author{
MATHIAS SCHANNOR ${ }^{1}$, HEYE FREYMUTH ${ }^{1}$, JESSE R \\ REIMINK $^{2}$, MARK REHKÄMPER ${ }^{3}$ AND HELEN M \\ WILLIAMS $^{1}$
}

${ }^{1}$ University of Cambridge

${ }^{2}$ Pennsylvania State University

${ }^{3}$ Imperial College London

Presenting Author: mss77@cam.ac.uk

Earth's oldest continental crust is found in cratonic nuclei comprised of tonalite-trondhjemite-granodiorites (TTGs). However, the nature of the source materials that formed TTGs, as well as the timing and mechanisms of its formation remain controversial. The two endmember tectonic models for the formation of Archean TTGs are (i) vertical subduction and partial melting of the subducting hydrated oceanic crust, (ii) partial melting at the base of plume-generated oceanic plateaux $[1,2]$. The thallium stable isotope composition of magmatic rocks can identify distinct components in modern subduction zone settings $\left(\varepsilon^{205} \mathrm{Tl}\right.$ of primitive mantle $=-2$, altered oceanic crust $=-2$ to -16 ; [3]) and thus can be exploited to address early continental crust formation. Here we report $\mathrm{Tl}$ isotope compositions for rocks from the Acasta Gneiss Complex (AGC) in Canada, which contains the oldest known evolved crust, with igneous crystallization ages ranging from 4.03 to 2.95 Gyr [4]. Orthogneisses of the AGC have $\varepsilon^{205} \mathrm{Tl}$ values in the range of -3.1 \pm 0.2 to $-1.1 \pm 0.4$, where lower values are consistent with the mixing of mantle melts and hydrothermally altered, hydrated oceanic crust.

Recently, titanium isotope data of the AGC revealed a transition from tholeiite- to calc-alkaline-style magmas at the Hadean-Archean boundary, indicating an evolution from magmatism in plume settings to convergent arcs [5]. This evolution coincides with progressively lighter $\mathrm{Tl}$ isotope compositions of orthogneisses from 4.02 to 3.57 Gyr. Thus, Tl isotopes suggest that the change of geodynamic setting for TTG formation in the AGC is accompanied by a transition to melting of a source that was previously altered by surface waters.

[1] Foley et al. (2002) Nature 417, 637-740. [2] Zegers \& Van Keken (2001) Geology 29, 1083-1086. [3] Nielsen et al. (2017) Rev Mineral Geochem 82, 759-798. [4] Bowring et al. (1989) Geology 17, 971-975. [5] Aarons et al. (2020) Science Advances 6, eabc9959 